\title{
Colonizing the east and the west: distribution and niche properties of a dwarf Asian honey bee invading Africa, the Middle East, the Malay Peninsula, and Taiwan
}

\author{
Daniel P. Silva ${ }^{1}$, Ana Carollina F. CASTRO ${ }^{2}$, Bruno Vilela ${ }^{3}$, Xin Rui ONG ${ }^{4}$, \\ Jennifer C. Thomas ${ }^{5}$, Abdulaziz S. Alqarni ${ }^{6}$, Michael S. Engel ${ }^{7,8}$, John S. Ascher $^{4}$ \\ ${ }^{1}$ COBIMA Lab, Departamento de Ciências Biológicas, Instituto Federal Goiano, Rodovia Geraldo Silva Nascimento, km \\ 2.5, Zona Rural, Urutaí, Goiás 75790-000, Brazil \\ ${ }^{2}$ Programa de Pós-Graduação em Biodiversidade Animal, Instituto de Ciências Biológicas Universidade Federal de \\ Goiás, Campus II, Goiânia, GO 740001-970, Brazil \\ ${ }^{3}$ Instituto de Biologia, Universidade Federal da Bahia, Rua Barão de Geremoabo, 147, Ondina, Salvador, Bahia 74001- \\ 970, Brazil \\ ${ }^{4}$ Insect Diversity Lab, Department of Biological Sciences, National University of Singapore, 16 Science Drive 4, \\ Singapore 117558, Singapore \\ ${ }^{5}$ Division of Entomology, Natural History Museum, University of Kansas, 1501 Crestline Drive-Suite 140, Lawrence, \\ KS 66045-4415, USA \\ ${ }^{6}$ Department of Plant Protection, College of Food and Agriculture Sciences, King Saud University, P.O. Box 2460, \\ Riyadh 11451, Saudi Arabia \\ ${ }^{7}$ Division of Entomology, Natural History Museum, and Department of Ecology \& Evolutionary Biology, University of \\ Kansas, 1501 Crestline Drive-Suite 140, Lawrence, KS 66045-4415, USA \\ ${ }^{8}$ Division of Invertebrate Zoology, American Museum of Natural History, Central Park West at 79th Street, New York, \\ NY 10024-5192, USA
}

Received 15 January 2019 - Revised 3 October 2019 - Accepted 28 October 2019

\begin{abstract}
Species invasions are expected to increase continuously with undeniable impact upon native biodiversity, being an important process in relation to the decline of native pollinators. We used species distribution models and multivariate analyses to assess the climatic niche properties of the red dwarf honey bee, Apis florea Fabricius (Apidae: Apini), an open-nesting species native to southern Asia and parts of the Middle East, currently invading East Africa, Sundaic tropical Southeast Asia (Peninsular Malaysia and Singapore), and East Asia (Taiwan). The species' niche was relatively conserved, with the climatic conditions in all its invaded range overlapped by those from its native one. Its potential distribution in Africa and the Indomalayan region is broad, with anthropogenic areas likely providing new habitats and dispersal corridors in areas that were formerly too arid or too heavily forested to allow its dispersal. Future studies to evaluate the potential impacts of $A$. florea in invaded ranges are encouraged.
\end{abstract}

species distribution models / macroecology / invasion process / Asia / Africa

Electronic supplementary material The online version of this article (https://doi.org/10.1007/s13592-019-00711-x) contains supplementary material, which is available to authorized users.

Corresponding author: D. Silva, daniel.paivasilva@gmail.com Manuscript editor: Marina Meixner

\section{INTRODUCTION}

Species invasions constitute one of the main drivers of biodiversity loss today, along with habitat loss and fragmentation, environmental deposition of nitrogen and phosphorus, and the expected climate change due to the emission of $\mathrm{CO}_{2}$ and 
other greenhouse gases (Tylianakis et al. 2008). Invasive species may cause significant ecological problems in the regions they invade, since they generally are important competitors and may eventually become abundant in such adventive areas, altering species interspecific interactions and the availability of natural resources (Pejchar and Mooney 2009). This may significantly impact humanity's relationship with nature and thereby cause economic losses in the scale of billions of dollars per annum (Pimentel et al. 2005).

The invasion process is usually divided into different phases (Richardson et al. 2000; Blackburn et al. 2011). In the initial phase, propagules of the invasive species trespass geographic barriers that keep them in their native ranges and, consequently, reach new distributional areas, although most of these propagules do not establish in the new localities. Eventually, those propagules that survive and reproduce may establish a stable population within the newly invaded localities. In the final invasion period, this newly naturalized population will produce new propagules from within invaded areas, and these new propagules may restart the whole process in a series of new locations.

Explaining why certain species can invade new areas is challenging. Two non-mutually compatible hypotheses attempt to explain such successes. One hypothesis assumes that invasive species go through a process of "enemy-release" while invading new ranges, temporarily freed of competitors and natural enemies that are otherwise capable of controlling the species' populations within its native range (Keane and Crawley 2002; Müller-Schärer and Schaffner 2008). The alternative hypothesis postulates that invasive species experience adaptive shifts that eventually lead to niche changes that allow for and explain their success while occupying new localities and ranges.

Another possibility is that anthropogenic creation of novel habitats provides new suitable areas, including dispersal corridors, in locations that did not originally have the climatic conditions tolerated by invading species. Such new habitats may allow invading species to transverse formerly unsuitable areas so as to reach formerly inaccessible sites with naturally more favorable climatic conditions. The creation of novel habitats can be due to deliberate urban greening (Hennig and Ghazoul 2012;
Braaker et al. 2014; Threlfall et al. 2017), as in the case of Arabian cities and Singapore, but can also be a by-product of larger-scale phenomena such as deforestation of the Thai-Malay Peninsula (Liow et al. 2001; Oldroyd and Nanork 2009), replacing unsuitable continuous humid forests with suitable more open habitats and drier microclimates.

From this perspective, current macroecological approaches unifying multivariate climatic analyses and species distribution models (SDM hereon) attempt to answer what occurs with the niche of an exotic species as it invades new areas (Guisan et al. 2014). These analyses make use of the increasing amount of collection occurrence records (Pyke and Ehrlich 2010) available from online databases (e.g., Global Biological Information Facility - GBIF; Centro de Referência em Informação Ambiental - CRIA's Species Link), along with historical climatic data easily available from the internet (e.g., WorldClim; Hijmans et al. 2005). This framework has been recently applied to several insect species and revealed that invasion success is usually dependent on different invasion histories, but also different ecological perspectives (Di Cola et al. 2017; Hill et al. 2017).

Considering bee species, some historic invasion events are well documented and studied, and a few studies use species distribution models to predict their distribution ranges in the recent literature. As for many other invasive species, these studies show that invasive bees are expected to invade large regions (e.g., Hinojosa-Díaz et al. 2005; Strange et al. 2011; Vital et al. 2012; Jarnevich et al. 2014). For instance, the European woolcarder bee Anthidium (Anthidium) manicatum (Linnaeus, 1758) (Megachilidae: Anthidiini), the woodborer bee Lithurgus huberi Ducke, 1907 (Lithurginae), and the giant resin bee Megachile (Callomegachile) sculpturalis Smith, 1853 (Megachilini) expanded their ranges from their native ranges and invaded different regions around the world (Hinojosa-Díaz et al. 2005; Strange et al. 2011; Silva et al. 2014). Recently, it has been suggested that $M$. sculpturalis is establishing new populations in Europe (e.g., Quaranta et al. 2014; Westrich et al. 2015; Le Feón et al. 2018), along with M. (Callomegachile) disjunctiformis Cockerell, 1911 (Hymenoptera: Megachilidae), a related species in the same subgenus (Bortolotti et al. 2018). 
Perhaps the most famous invasion among bees, however, is the Africanized honey bee, i.e., escaped populations derived from Apis (Apis) mellifera scutellata Lepeletier, 1836 (Apidae: Apini), which are intensively used in agricultural ecosystems. This species is claimed to cause significant ecological problems in its now widespread New World range (Butz-Huryn 1997; Goulson 2003; Paini 2004). Another species of subgenus Apis, the cavity-nesting A. (Apis) cerana Fabricius, 1793 (Apidae: Apinae) of South, Southeast, and East Asia has been introduced to islands of Melanesia (e.g., New Guinea, Solomon Islands) and has recently expanded its range to tropical Australia (Shield 2007). This species is expected to control resources to almost the same intensity observed for A. mellifera in Africa (Koetz 2013).

Finally, the red dwarf honey bee A. (Micrapis ) florea Fabricius, 1787 (Apini), a species originally from western and southern Asia and monsoonal Southeast Asia (Radloff et al. 2011), has been reported to have gradually expanded its range into the Middle East (Mossagegh 1993) and Arabia, and has more recently been discovered to be extending its range in eastern Africa (Bezabih et al. 2014; Shebl 2017), in regions of Sundaic Southeast Asia including the Malay Peninsula that were formerly too forested and instead occupied by its sister species A. (Micrapis) andreniformis Smith, 1858, and in Taiwan. Considering this new case of range increase in multiple continents by an invasive bee species, we explored the invasion history of A. florea in both African and Indomalaya ranges. Specifically, we (1) evaluate using multivariate analyses whether the climatic niche of the species shifted or was conserved during its invasion process, and (2) use SDMs to estimate the species' distribution in both its native and invaded areas.

\section{METHODS}

\subsection{Occurrences dataset}

We obtained occurrence records for A. florea from various data sources, including the Global Biological Information Facility (GBIF.org), CRIA's Species Link (http://splink.cria.org.br), and iNaturalist (http://www.inaturalist.org; identifications were made or verified by JSA). We also obtained records from major entomological collections: the Division of Entomology of the University of Kansas Natural History Museum (SEMC: Lawrence, KS), the American Museum of Natural History (AMNH: New York, NY), and the Department of Biological Sciences of the National University of Singapore (NUS). Occurrences with unreliable geographic information were disregarded. For the occurrences that had locality cited but no specific geographic information, we used Google Earth (Google Inc. 2018) to obtain geographic coordinates for the nearest municipality. In total, we obtained 1012 occurrences for the species, with 930 from the species' native distribution and 98 from areas outside its original distribution range (Figure 1). For all occurrences of A. florea we gathered, we provided the original source from where they were obtained in our supplementary materials. In Table S1, we provided the countries' names from where each occurrence was obtained. All occurrences are provided in a Supplementary File.

\subsection{Environmental variables and species distribution models}

We obtained environmental variables from the Worldclim database (Hijmans et al. 2005), considering a grid cell size resolution of 2.5 arc-min $\left(0.041^{\circ}\right.$ or $4 \mathrm{Km}$ at the equator), and the whole study area across both Africa and Asia (minimum longitude, $-18^{\circ}$; maximum longitude, $122^{\circ}$; minimum latitude, $-35^{\circ}$; maximum latitude, $42^{\circ}$ ). To reduce model overfitting in the distribution models for the species (Jiménez-Valverde et al. 2011), we applied a principal components analysis (PCA hereon) to create new orthogonal climatic variables (principal components; PCs hereon) to be used as the environmental predictors to estimate the distribution of $A$. florea. The seven selected PCs explained almost $96 \%$ of the original climatic variation.

We modeled the species' distribution with the obtained occurrence records using six different modeling methods: (1) the method of maximum entropy implemented in MaxEnt (MAX hereon; Phillips et al. 2006; Phillips and Dudík 2008), (2) Gaussian Model (GAU; Vanhatalo et al. 2012), 


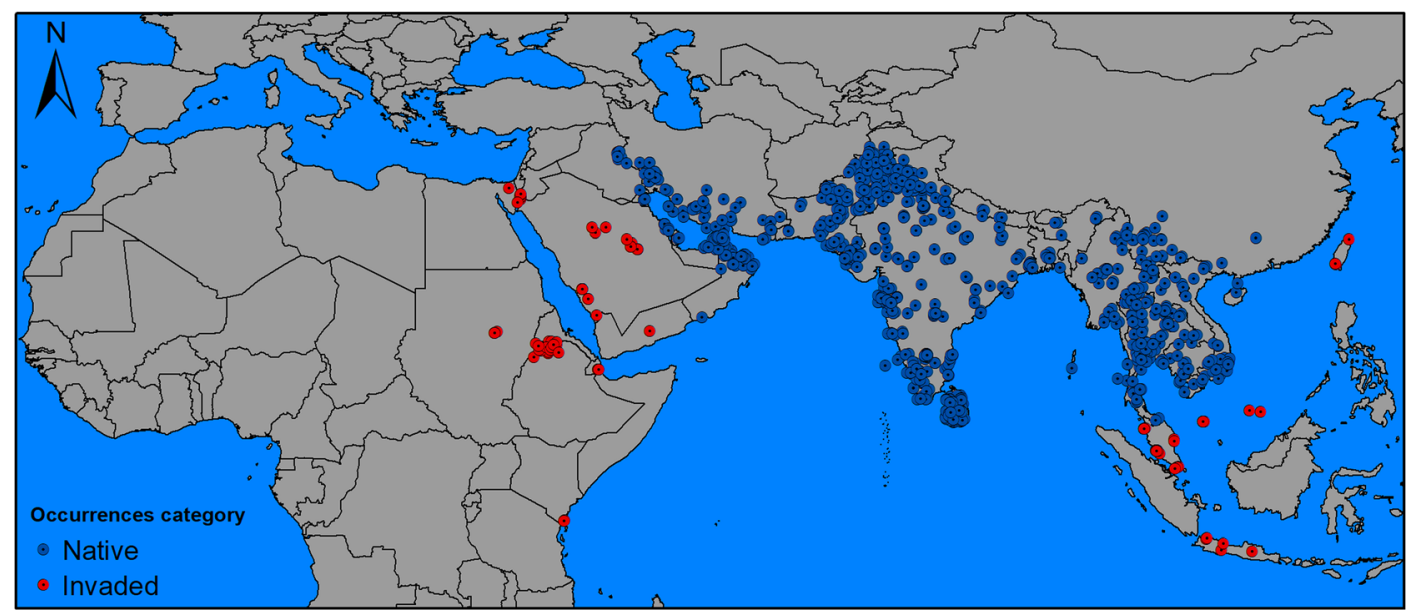

Figure 1. Occurrence data for Apis florea in its native (blue circles) and invaded (red circles) range within Africa and Asia.

(3), Generalized Linear Models (GLM hereon; Guisan et al. 2002), (4) Random Forest (RDF hereon; Breiman 2001), (5) Generalized Additive Models (GAM; Hastie and Tibshirani 1986), and (6) Support Vector Machines (SVM hereon; Schölkopf et al. 2001; Tax and Duin 2004; Guo et al. 2005).

We used all spatially unique occurrences to generate the models and partitioned them in a checkerboard fashion, with an aggregation factor of two. In this partition method, the occurrences are divided into two datasets, one of which is used to predict the species distribution and the other to evaluate the first distribution model produced. The latter dataset is also used to produce a second distribution model for the species, which is then evaluated by the dataset initially used to produce the species distribution in the first step (Muscarella et al. 2014; Roberts et al. 2017). We also used a shapefile of world ecoregions, obtained from World Wildlife Fund website (http://www.worldwildlife.org/biomes), to restrict the training area of our distribution models to climatic conditions of the ecoregions where known occurrences of the species are available. By using such methods, we decrease the effects of a random pseudo-absence allocation in the geographic space that may produce unreliable distributions for the target species (VanDerWal et al. 2009; Lobo and Tognelli 2011).
We considered the threshold that balances both omission and commission errors in order to cut the suitability matrices into presence/absence maps (Jiménez-Valverde and Lobo 2006, 2007). To evaluate the goodness-of-fit of our model, we used the true skill statistic (TSS hereon; Allouche et al. 2006), a threshold-dependent metric that varies from -1 to +1 , where models reaching values near to 0.5 are considered as acceptable and predictions reaching 0.7 or higher values are considered as excellent. Finally, we used all models with TSS values above the mean TSS value to produce the ensemble distribution for A. florea (Araújo and New 2007).

\subsection{Multivariate niche analyses}

We considered the 19 environmental variables from Wordlclim to perform the niche analysis and compared the environmental properties of A. florea in both its native and invaded ranges using the R package ecospat (Di Cola et al. 2017). We considered the same grid cell size and study extent used before. To establish a background area before starting the analyses, we created a $150-\mathrm{km}$ buffer around the species occurrences, where we sampled 1000 points (as done in Silva et al. 2016).

We performed the analyses based on the PCAenv methods proposed by the framework of Broennimann et al. (2012). This method considers 
pairwise comparisons of both niche and the density of occurrences, correcting for collection biases on occurrence records. It uses a smooth kernel density function and calculates a niche overlap score between each range (native vs. introduced ranges) of the species by using the Schoener's D metric (Schoener 1970). This metric varies from 0 to 1 , where 0 represents a complete dissimilarity between the compared ranges and 1 represents a complete similarity between the compared ranges. The method performs two different randomization tests of the occurrence records to evaluate whether the climatic niche of the species shifted when it invaded the new range. In the first, it performs niche equivalence tests to check whether the observed niche overlap value is different than what would be expected by chance alone. The second randomization test computes niche similarity tests and compares the niche overlap of one range distributed at random over its background area, while keeping the other range unchanged (native range $\rightarrow$ invaded range). The method is also capable of performing the same analysis with the range which was originally kept unchanged in the first procedure (native range $\leftarrow$ invaded range). Nonetheless, since this comparison is not of our interest, since the invasion process occurs from the native to the invaded ranges, we did not considered this analysis direction in our study. In this test, these comparisons are repeated 100 times to allow the production of a null distribution of random overlap values to be compared with the value from the real occurrences of the species in each of its ranges, as proposed by Warren et al. (2008). In the event where the observed overlap is significantly smaller than those values obtained at random, it means the species occupies different segments of environmental space in both occupied ranges. Following these procedures, we obtained the proportion of the climatic niches from the compared ranges that suffered expansion, remained stable, or were unfilled during the invasion process.

We measured the amount of niche stability, niche expansion, and niche unfilling between both native vs. invaded ranges of $A$. florea (sensu Guisan et al. 2014). In these analyses, we do comparisons of the available analog climatic conditions in areas that may or may not be occupied by the species, but that are available for its colonization within both ranges with those in fact occupied by the species in both ranges. If there is a high overlap of available and occupied analog climatic conditions between both ranges, there is a high proportion of stabilized niche for the species in each range. If the overlap of climatically analog and occupied conditions in both ranges is low, the species would have a high proportion of its niche unfilled. In both scenarios, the general expectation is that no niche shift is expected to have occurred. Finally, if the overlap of analog climatic conditions available is high between each range, but the overlap of occupied conditions by the species is low or nonexistent, then we can assume the species' niche is expanding in the invaded range, with a consequent niche shifting/unfilling if compared with the native range.

\section{RESULTS}

\subsection{Distribution models for Apis florea}

Our species distribution models for A. florea reached a mean TSS value of $0.927 \pm 0.026$ (mean \pm standard deviation; $n=6$ models). The RDF method yielded the highest TSS value (0.960), followed by MAX (0.948), SVM (0.937), GAU (0.910), GAM (0.898), and GLM (0.879). Only MAX (Figure 2d) showed more overprediction of the distribution of $A$. florea and included several suitable areas in the Sahara Desert.

Based on all methods, the predictions produced for A. florea show suitable regions currently without reported occurrences of the species. For instance, several regions in east and southeast China, Indonesia (e.g., Sumatra, Kalimantan, and Sulawesi), and also Taiwan, where A. florea has been recently reported, were indicated as potentially suitable. Additionally, regions from the Middle East (e.g., Saudi Arabia, Israel) and the subSaharan Africa (several countries) and North Africa (Morocco to Egypt) were predicted as suitable for the species (Figure 2a-f). Several areas in western, sub-Saharan, and southern Africa were also indicated as suitable for potentially invasion by A. florea. The species' final ensemble distribution model, based on the weighted distribution that considered the independent results produced 


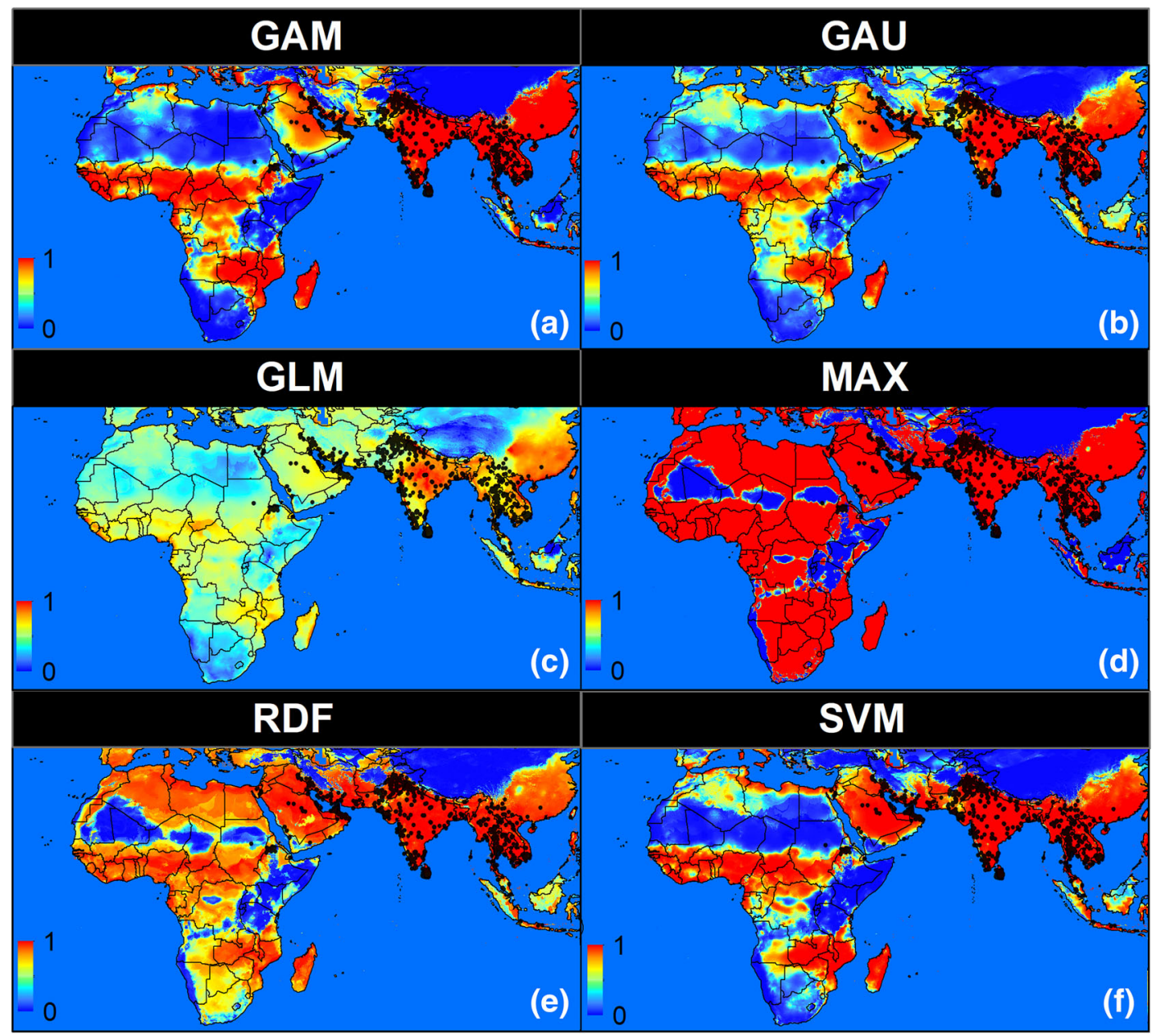

Figure 2. Model predictions for Apis florea based on the six modeling methods: a GAM, b GAU, c GLM, d MAX, e RDF, and f SVM. Warmer colors represent high suitability for each method employed to predict the bee's current distribution range, while colder colors represent areas with low suitability. Scale bar represents the suitability map. Occurrences for A. florea are depicted with black dots in all maps.

by all modeling methods, is shown in Figure 3 a (mean suitability values map) and b (presence/ absence maps).

\subsection{Multivariate niche properties of Apis florea}

In our multivariate niche analyses, the first two PCA axes explained $\sim 70 \%(42.06 \%$ and $27.48 \%$, respectively) of the original environmental variables considered. The contributions of each variable for each one of the PCA axes are shown in Figure 4a, b and the composed PCA plot is shown in Figure 4c.
The pairwise comparisons between the native and invaded ranges of $A$. florea yielded a relatively low Schoener's $D$ value of 0.089 , indicating a low niche overlap proportion between the two distribution range classes (Figure 4d). The niche similarity test indicated no changes in the niche of $A$. florea as it invaded previously unoccupied regions ( $p$ value from the native range to the invaded one was 0.198). The proportion of unfilled niche from the native to the exotic range was 0.506 and that of expansion was 0 from the native to the invaded range. In summary, these values indicate that climatic conditions for the species in 


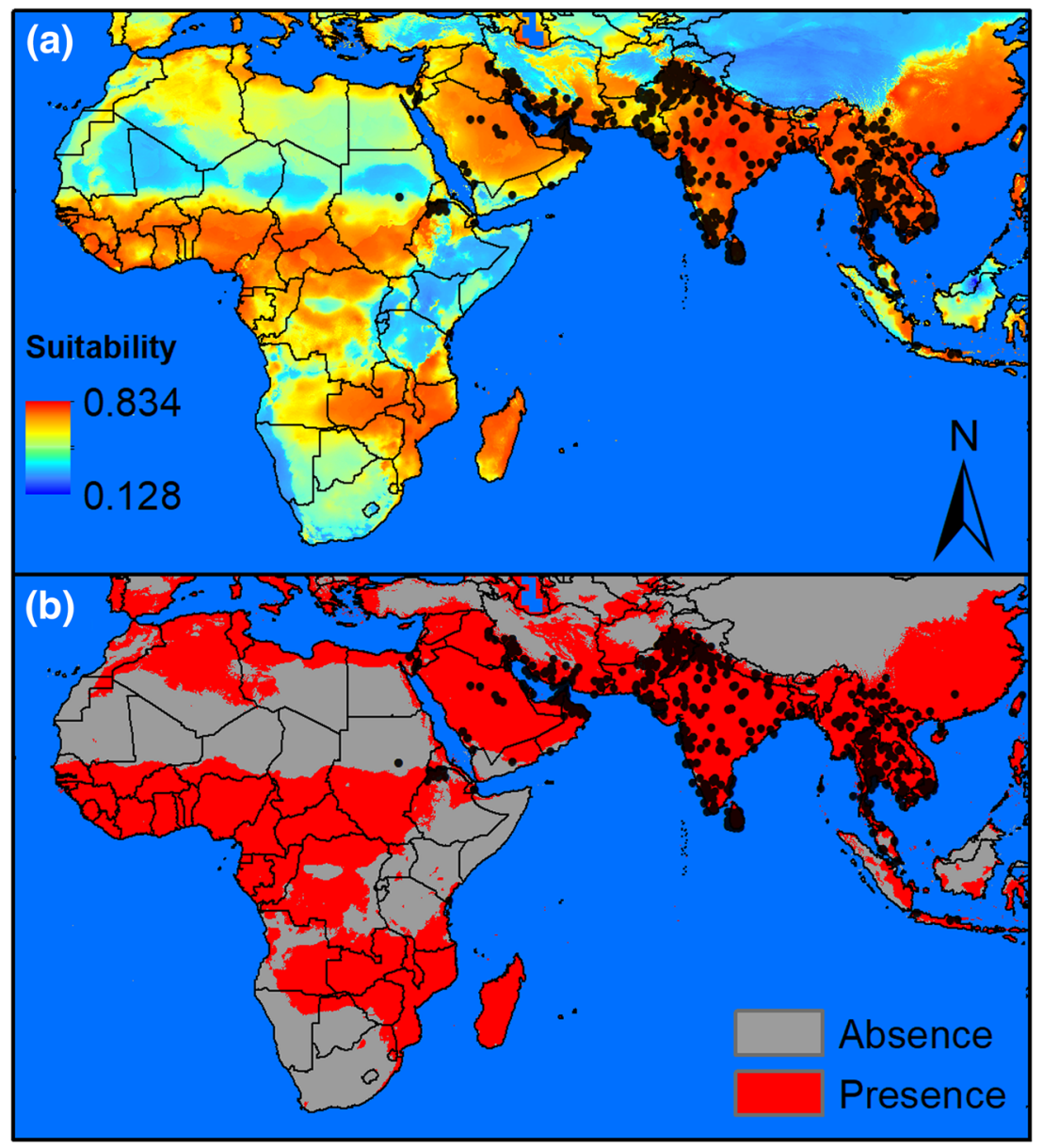

Figure 3. Results of the species distribution models obtained for Apis florea, considering a the species' suitability gradient and $\mathbf{b}$ the presence/absence map. In $\mathbf{a}$, warmer colors represent high suitability for each method employed to predict the bee's current distribution range, while colder colors represent areas with low suitability. Scale bar represents the suitability map. Occurrences for A. florea are depicted with black dots in both maps.

its invaded range are not different from those in its native one. All these results are show in Table I.

\section{DISCUSSION}

Using multivariate analyses, we demonstrated that the climatic niche of $A$. florea is generally conserved, even though there was a significant proportion of niche unfilling $(0.506)$ when we compared the climatic conditions in areas occupied by the bee in both of its native and invaded ranges. In general, the species showed a small proportion of overlap between the climatic conditions within its native and invaded ranges, but all the climatic conditions from the invaded niche were found within the native one. Therefore, in general, the climatic conditions in the invaded range are essentially the same as those in the native one. Such climatic conditions occurred even with a broad potential geographic range of the species, as detected by our distribution modeling procedures. We showed in our SDMs that the potential distribution of this species is wide, extending from its core range in South and Southeastern Asia to include to southern China and Taiwan, 
(a)



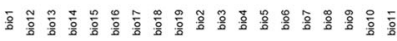

(b)

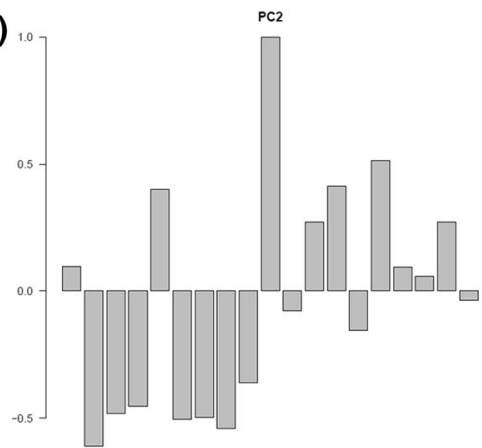

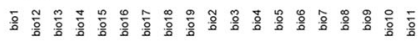

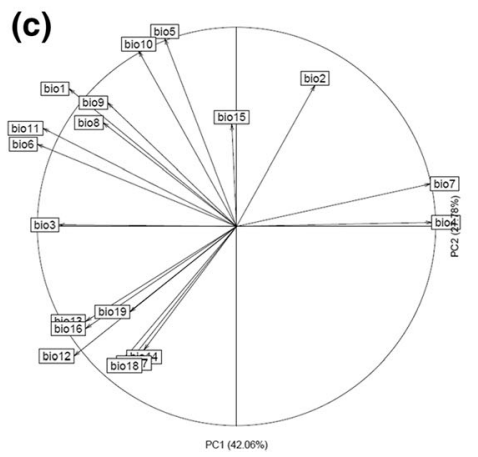

(d)

(e)
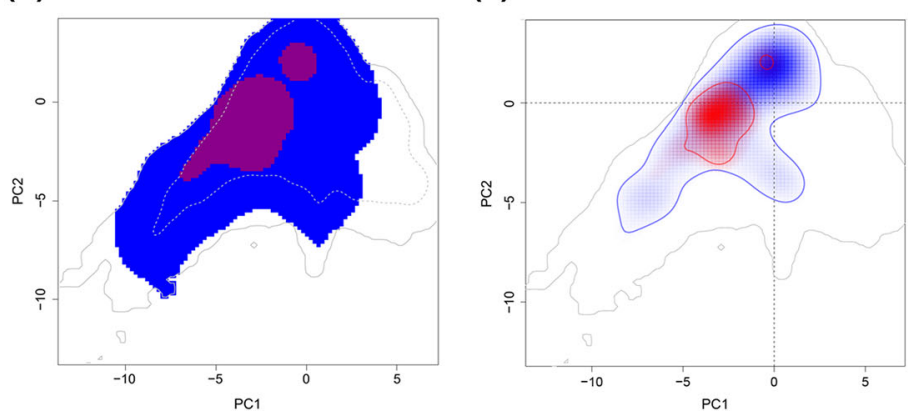

Figure 4. Results of multivariate niche analyses. Explanation of the original climatic variation by the $\mathbf{a}$ first and $\mathbf{b}$ second PCA axes from the PCA-env analyses from Broennimann et al. (2012). c The first two PCA axes and orientation of all environmental variables in each axis. d Overlap of the realized climatic niches of Apis florea, representing the stable (purple) and unfilled (red) niche proportions, when comparing its invaded with its native ranges. There was no niche expansion. Outermost and thicker line represent $100 \%$ of available climatic conditions for the species in each range. Dotted middle lines correspond to $50 \%$ of available climatic conditions for the species in each range. e Overlap of the realized niches of Apis florea in all its considered (native and invaded) ranges. Native: blue; invaded: red. The solid lines represent $10 \%$ of the occurrences density in each range.

Table I. Pairwise comparisons of niche overlap $(D)$, niche similarity $p$ value, niche unfilling, niche stability, and niche expansion between the native and invaded ranges (direction: native range $\rightarrow$ invaded range) of Apis florea following Broennimann et al. (2012). The direction invaded range $\rightarrow$ native range was not considered, since the invasion process does not occur in this fashion

\begin{tabular}{ll}
\hline Statistic & $\begin{array}{l}\text { Direction } \\
\text { Native } \rightarrow \text { invaded }\end{array}$ \\
\hline Schoener's $D$ & 0.089 \\
Similarity test ( $p$ value) & 0.198 \\
Niche unfilling & 0.506 \\
Niche stability & 0.494 \\
Niche expansion & 0.000 \\
\hline
\end{tabular}

Peninsular Malaysia, Singapore, and most of the African continent.

One major issue when discussing the effects of invasive pollinators is their potential impact on native species inhabiting the invaded regions. Although estimations of their effects are generally lacking, when considering A. mellifera, Cane and Tepedino (2017) were able to estimate that the amount of resources gathered by a single colony of this species would prevent the production of 100,000 native bees. Such pernicious and pervasive effects are in agreement with previous analyses (Butz-Huryn 1997; Goulson 2003; Paini 2004; Paini et al. 2016). 
Considering the known floral resource control and monopolization by A. mellifera [in the Americas (Cane and Tepedino 2017)] and A. cerana [in Southeast Asia (Koetz 2013)], if the behavior of $A$. florea overlaps with that of its related species, native pollinators are expected to suffer some competition.

Evaluating the niche conservatism we obtained for A. florea from its native range to its invaded one and the predicted distribution in Africa and Southeast Asia, we expect that this bee is able to expand its range considerably. Particularly, the establishment of new populations is expected to occur in those locations where human activity is intense, i.e., among plantings and irrigated lands within urban green spaces (Hennig and Ghazoul 2012; Braaker et al. 2014; Threlfall et al. 2017), as well as in areas where the native dipterocarp forests have been removed (Liow et al. 2001; Oldroyd and Nanork 2009). For the distribution of A. florea in Africa, we also expect that such processes (human activities and forest deforestation) may, in some degree, allow this species to increase its distribution. Regarding the new occurrence records reported for Taiwan, extensive trade involving the island has probably led to ship transportation of swarms to its major ports and establishment of new populations in an environment that is suitable but was previously unreachable for the species.

In the analyses we used here, we only dealt with the climatic conditions of the areas occupied by the species in each one of its ranges, and no deeper considerations related to the biotic interactions and dispersal capacities of the species were covered. Considering the BAM (Biotic-Abiotic-Dispersal) diagram proposed by Soberón (2007), alongside with abiotic environmental conditions, the distribution of a species is also determined by the biotic interactions it maintains with other species and by its dispersal capabilities. Therefore, even though our models predicted a wide potential distribution range, biotic interactions with native species already established in the areas it is invading may, in the end, prevent the species from effectively occupying these areas and developing viable populations.
The native habitats for $A$. florea in the Middle East, without human interference, were unsuitable under the current natural conditions due to aridity and lack of adequate vegetation that might provide yearround floral resources. Nonetheless, massive planting of irrigated gardens has created unprecedented favorable habitat in what would otherwise be climatically suitable areas. These anthropogenic sites may help A. florea to reach formerly inaccessible natural oases with favorable conditions.

In Southeast Asia, A. florea along with a potentially large number of Hymenoptera and other animals are adapted to more seasonal conditions, where more open vegetation prevails (e.g., in Central Thailand). Under natural conditions, southernmost Thailand and the Malay Peninsula were unsuitable to this species due to the occurrence of dense, humid, dipterocarp rainforest. Nonetheless, widespread deforestation of the Thai-Malay Peninsula has removed unsuitable dense forests and replaced them with far more open vegetation with a drier microclimate, thus rendering vast newly suitable (and/or accessible) areas for A. florea. Due to lack of data for key areas, such as conflict zones in southern Thailand, it is difficult to assess whether recent occurrences in the Malay Peninsula are the result of continuous spread of the bees from their core range in south Thailand through deforested landscapes, or if populations in places like Singapore were founded by colonies transported by ship. These scenarios, which are potentially testable using phylogeographic or population genomic datasets, are not mutually exclusive and both are plausible considering the known colonization of A. florea of Taiwan and Jakarta by ship.

Both in its native and in its introduced range (e.g., Singapore), A. florea thrives alongside large populations of three other species of Apis, including its closest relative A. andreniformis. Clearly, these species do not exclude each other at large spatial scales. At local scales, A. andreniformis predominates in the most mesic and densely forested semi-natural sites, whereas A. florea thrives in more open, drier, human-modified sites and is 
so far undetected in Singapore's most intact primary forest remnant (Ascher et al. 2019). It is not clear to what extent if any direct competition explains this pattern as opposed to differing niches.

Whether the invasive species' niche is conserved or shifting needs to be assessed to better predict if and how the invasion may impact local bee communities. The Multivariate and SDM methods used to study the invasion of $A$. florea have been used previously to evaluate the how invasion processes took place when considering other taxa in new ranges (Petitpierre et al. 2012; Strubbe et al. 2013; Silva et al. 2016). For 22 invasive insect species, Hill et al. (2017) showed that 12 had expanded their climatic niches in comparison to the climatic conditions within their native range. Moreover, among those 22 species, 15 also showed a significant level of niche unfilling, meaning that they still do not occupy the same climatic conditions they do in their native ranges, which indicates they may still yet go on to occupy even larger geographic areas. The unfilled proportion of climatic conditions of $A$. florea's niche when comparing the native and invaded ranges is a clear indication that this species is in climatic equilibrium with the climatic conditions available in its native range. Still, considering the amount of climatic conditions it occupies in its native range that is still not occupied in its invaded one, the large distribution range for $A$. florea we predicted with our SDMs is possible to occur in the future.

Based on our results, we encourage new studies attempting to evaluate the potential impacts of $A$. florea upon the community of native pollinators in Africa, and whether this bee has the potential to cause the same kind of harm to native species as its largerbodied, cavity-nesting relatives A. mellifera and $A$. cerana are doing elsewhere. Lastly, considering the available toolbox to determine climatic niche shift/conservatism and a recent publication enumerating several invasive bee species throughout the world (Russo 2016), we also believe a proper analysis of the invasive potential of these bee species is greatly needed. It is impossible to precisely determine at the moment the degree to which A. florea may impact co-occurring native pollinators in the sub-Saharan African and Southeast Asian regions predicted by our SDMs as suitable for the species. Nonetheless, the potential of this and other exotic species to impose a negative impact on native bees should serve as a call to critically evaluate the influence of exotic bees and other Hymenoptera.

\section{ACKNOWLEDGMENTS}

The authors thank three independent reviewers who provided significant suggestions that considerably improved a previous version of this study.

\section{AUTHOR CONTRIBUTION}

DPS and MSE conceived this research and designed the experiments; MSE, JSA, JCT, ASA, and MSE provided the data; DPS, ACFC, and BV analyzed the data; and DPS, ACFC, BV, JSA, JCT, ASA, XRO, and MSE wrote the paper.

\section{FUNDING INFORMATION}

The International Scientific Partnership Program (ISPP) at King Saud University through ISPP \#0083 supported parts of this project. Also, this study was financed in part by the Coordenação de Aperfeiçoamento de Pessoal de Nível Superior Brazil (CAPES), while the compilation of distributional records was supported in part by the National Research Foundation Singapore grant R-154-000-673-651.Colonisation à l'Est et à l'Ouest: Distribution et caractéristiques de niche d'une abeille naine asiatique migrant vers l'Afrique, le Moyen-Orient, la péninsule malaise et Taiwan.

modèles de répartition des espèces / macroécologie / processus d'invasion / Asie / Afrique.

Sie kolonisiert den Osten und den Westen: Verbreitung und Nischeneigenschaften einer Zwerghonigbiene, die nach Afrika, in den Mittkeren Osten, in die malaiische Halbinsel und nach Taiwan einwandert. 
Artverbreitungsmodelle / Makroökologie / Invasionsprozess / Asien / Afrika.

\section{REFERENCES}

Allouche, O., Tsoar, A., Kadmon, R. (2006) Assessing the accuracy of species distribution models: Prevalence, Kappa and the True Skill Statistic (TSS). J. Appl. Ecol. $43,1223-1232$.

Araújo, M., New, M. (2007) Ensemble forecasting of species distributions. Trends Ecol. Evol. 22 , 42-47.

Ascher, J.S., Soh, Z.W.W., Ho, B.M., Lee, R.Y.Y., Leong, A.Q.E., Chui, S.X., Lai., J.J.L., Lee, J.X.Q., Foo, M.S. (2019) Bees of the Bukit Timah Nature Reserve and vicinity. Gard Bull Singapore 71, 245-271.

Bezabih, G., Adgaba, N., Hepburn, H.R., Pirk, C.W.W. (2014) The territorial invasion of Apis florea in Africa. Afr. Entomol. 22, 888-890.

Blackburn, T.M., Pyšek, P., Bacher, S., Carlton, J. T., Duncan, R. P., et al (2011) A proposed unified framework for biological invasions. Trends Ecol. Evol. 26, 333-339.

Bortolotti, L., Luthi, F., Flaminio, S., Bogo, G., Sgolastra, F. (2018). First record of the Asiatic bee Megachile disjunctiformis in Europe. Bull. Insectology 71, 143149.

Braaker, S., Ghazoul, J., Obrist, M.K., Moretti, M. (2014) Habitat connectivity shapes urban arthropod communities: the key role of green roofs. Ecology 95 , 10101021.

Breiman, L. (2001) Random forests. Mach. Learn. 45, 532.

Broennimann, O., Fitzpatrick, M.C., Pearman, P.B., Petitpierre, B., Pellissier, L., et al. (2012) Measuring ecological niche overlap from occurrence and spatial environmental data. Glob. Ecol. Biogeogr. 21 , 481-497.

Butz-Huryn, V.M. (1997) Ecological impacts of introduced honey bees. Q. Rev. Biol. 72, 275-297.

Cane, J.H., Tepedino, V.J. (2017) Gauging the effect of honey bee pollen collection on native bee communities. Conserv. Lett. 10, 205-210.

Di Cola, V., Broennimann, O., Petitpierre, B., Breiner, F. T., D'Amen, M., et al (2017) ecospat: an R package to support spatial analyses and modeling of species niches and distributions. Ecography 40, 774-787.

Google Inc. (2018) Google Earth, version 7.0.3.8542

Goulson, D. (2003) Effects of introduced bees on native ecosystems. Annu. Rev. Ecol. Evol. Syst. 34, 1-26.

Guisan, A., Edwards, T.C., Hastie, T. (2002) Generalized linear and generalized additive models in studies of species distributions: Setting the scene. Ecol. Modell. 157, 89-100.

Guisan, A., Petitpierre, B., Broennimann, O., Daehler, C., Kueffer, C. (2014) Unifying niche shift studies:
Insights from biological invasions. Trends Ecol. Evol. 29, 260-269.

Guo, Q.H., Kelly, M., Graham, C.H. (2005) Support vector machines for predicting distribution of sudden oak death in California. Ecol. Modell. 182, 75-90.

Hastie, T., Tibshirani, R. (1986) Generalized Additive Models. Stat. Sci. 1, 297-310.

Hennig, E.I., Ghazoul, J. (2012) Pollinating animals in the urban environment. Urban Ecosyst 15, 149-166.

Hijmans, R.J., Cameron, S.E., Parra, J.L., Jones, P. G., Jarvis, A. (2005) Very high resolution interpolated climate surfaces for global land areas. Int. J. Climatol. 25, 1965-1978.

Hill, M.P., Gallardo, B., Terblanche, J.S. (2017) A global assessment of climatic niche shifts and human influence in insect invasions. Glob. Ecol. Biogeogr. 26, 679-689.

Hinojosa-Díaz, I.A., Yáñez-Ordóñez, O., Chen, G., Peterson, A. T., Engel, M. S. (2005) The North American invasion of the giant resin bee (Hymenoptera: Megachilidae). J. Hymenopt. Res. 14, 69-77.

Jarnevich, C.S., Esaias, W.E., Ma, P.L.A., Morisette, J. T., Nickeson, J. E. et al. (2014) Regional distribution models with lack of proximate predictors: Africanized honeybees expanding north. Divers. Distrib. 20, 193201. doi: https://doi.org/10.1111/ddi.12143

Jiménez-Valverde, A., Lobo, J.M. (2006) The ghost of unbalanced species distribution data in geographical model predictions. Divers. Distrib. 12, 521-524.

Jiménez-Valverde, A., Lobo, J.M. (2007) Threshold criteria for conversion of probability of species presence to either-or presence-absence. Acta Oecologica, 31, 361-369.

Jiménez-Valverde, A., Peterson, A.T., Soberón, J., Overton, J. M., Aragón, P., et al. (2011) Use of niche models in invasive species risk assessments. Biol. Invasions 13, 2785-2797.

Keane, R.M., Crawley, M.J. (2002) Exotic plant invasions and the enemy release hypothesis. Trends Ecol. Evol. 17, 164-170.

Koetz, A. (2013) Ecology, behaviour and control of Apis cerana with a focus on relevance to the Australian incursion. Insects 4, 558-592.

Le Feón, V., Aubert, M., Genoud, D., Andrieu-Ponel, V., Westrich, P., et al (2018) Range expansion of the Asian native giant resin bee Megachile sculpturalis (Hymenoptera, Apoidea, Megachilidae) in France. Ecol. Evol. 8, 1534-1542.

Liow, L.H., Sodhi, N.S., Elmqvist, T. (2001) Bee diversity along a disturbance gradient in tropical lowland forests of south-east Asia. J Appl Ecol 38, 180-192.

Lobo, J.M., Tognelli, M.F. (2011) Exploring the effects of quantity and location of pseudo-absences and sampling biases on the performance of distribution models with limited point occurrence data. J. Nat. Conserv. 19, 1-7.

Mossagegh, M.S. (1993) New geographical distribution line of Apis florea in Iran. In: Conner LJ, Rinderer T, 
Sylvester HA, Wongsiri S (eds) Asian Apiculture, 1st edn. Wicwas Press, Cheshire, pp 64-66

Müller-Schärer, H., Schaffner, U. (2008) Classical biological control: Exploiting enemy escape to manage plant invasions. Biol. Invasions 10, 859-874.

Muscarella, R., Galante, P.J., Soley-Guardia, M., Boria, R. A., Kass, J. M., et al (2014) ENMeval: An R package for conducting spatially independent evaluations and estimating optimal model complexity for Maxent ecological niche models. Methods Ecol. Evol. 5, 11981205.

Oldroyd, B., Nanork, P. (2009) Conservation of Asian honey bees. Apidologie 40, 296-312

Paini, D.R. (2004) Impact of the introduced honey bee (Apis mellifera) (Hymenoptera: Apidae) on native bees: A review. Austral Ecol. 29, 399-407.

Paini, D.R., Sheppard, A.W., Cook, D.C., De Barro, P.J., Worner, S. P., et al. (2016) Global threat to agriculture from invasive species. Proc Natl Acad Sci USA 113 , 7575-7579.

Pejchar, L., Mooney, H.A. (2009) Invasive species, ecosystem services and human well-being. Trends Ecol. Evol. 24, 497-504.

Petitpierre, B., Kueffer, C., Broennimann, O., Randin, C., Daehler, C., et al. (2012) Climatic niche shifts are rare among terrestrial plant invaders. Science 335, 1344 1348.

Phillips, S.J., Anderson, R.P., Schapire, R.E. (2006) Maximum entropy modeling of species geographic distributions. Ecol. Modell. 190 , 231-259.

Phillips, S.J., Dudík, M. (2008) Modeling of species distributions with Maxent: New extensions and a comprehensive evaluation. Ecography 31, 161-175.

Pimentel, D., Zuniga, R., Morrison, D. (2005) Update on the environmental and economic costs associated with alien-invasive species in the United States. Ecol. Econ. 52, 273-288.

Pyke, G.H., Ehrlich, P.R. (2010) Biological collections and ecological/environmental research: A review, some observations and a look to the future. Biol. Rev. 85, 247-266.

Quaranta, M., Sommaruga, A., Balzarini, P., Felicioli, A. (2014) A new species for the bee fauna of Italy: Megachile sculpturalis continues its colonization of Europe. Bull. Insectology 67, 287-293.

Radloff, S.E., Hepburn, H.R., Engel, M.S. (2011) The Asian species of Apis. In: Hepburn HR, Radloff SE (eds) Honeybees of Asia, 1st edn. Springer, Berlin, pp $1-22$.

Richardson, D.M., Pysek, P., Rejmanek, M., Wightman, J., Simmonds, C., et al. (2000) Naturalization and invasion of alien plants: concepts and definitions. Divers. Distrib. 6, 93-107.
Roberts, D.R., Bahn, V., Ciuti, S., Boyce, M. S., Elith, J., et al. (2017) Cross-validation strategies for data with temporal, spatial, hierarchical, or phylogenetic structure. Ecography 40, 913-929.

Russo, L. (2016) Positive and negative impacts of nonnative bee species around the world. Insects 7, 69 .

Schoener, T.W. (1970) Nonsynchronous spatial overlap of lizards in patchy habitats. Ecology, 51, 408-418.

Schölkopf, B., Platt, J.C., Shawe-Taylor, J., Smola, A. J., Williamson, R. C. (2001) Estimating the support of a high-dimensional distribution. Neural Comput. 13, 1443-71.

Shebl, M.A. (2017) Discovery of Apis florea colonies in northeastern Egypt. African Entomol. 25 , 248-248.

Shield, J. (2007) The Asian Honey Bee: Report of an incursion in Cairns 2007 - Technical aspects of the response. Department of Primary Industries and Fisheries (Ed.). Brisbane: pp: 1-106.

Silva, D.P., Gonzalez, V.H., Melo, G.A.R., Lucia, M., Alvarez, L. J., et al. (2014) Seeking the flowers for the bees: Integrating biotic interactions into niche models to assess the distribution of the exotic bee species Lithurgus huberi in South America. Ecol. Modell. 273, 200-209.

Silva, D.P., Vilela, B., Buzatto, B.A., Moczek, A. P., Hortal, J. (2016) Contextualized niche shifts upon independent invasions by the dung beetle Onthophagus taurus. Biol. Invasions 18, 3137-3148.

Soberón, J., 2007. Grinnellian and Eltonian niches and geographic distributions of species. Ecol Lett 10, 1115-1123.

Strange, J.P., Koch, J.B., Gonzalez, V.H., Nemelka, L., Griswold, T. (2011) Global invasion by Anthidium manicatum (Linnaeus) (Hymenoptera: Megachilidae): assessing potential distribution in North America and beyond. Biol. Invasions 13, 2115-2133.

Strubbe, D., Broennimann, O., Chiron, F., Matthysen, E. (2013) Niche conservatism in non-native birds in Europe: Niche unfilling rather than niche expansion. Glob. Ecol. Biogeogr. 22, 962-970.

Tax, D.M.J., Duin, R.P.W. (2004) Support vector data description. Mach. Learn. 54, 45-66.

Threlfall, C.G., Mata, L., Mackie, J.A., Hahs, A. K., Stork, N. E., Williams, N. S.G., Livesley, S. J. (2017) Increasing biodiversity in urban green spaces through simple vegetation interventions. J Appl Ecol 54, 1874-1883.

Tylianakis, J.M., Didham, R.K., Bascompte, J., Wardle, D.A. (2008) Global change and species interactions in terrestrial ecosystems. Ecol. Lett. 11, 1351-1363.

VanDerWal, J., Shoo, L.P., Johnson, C.N., Williams, S.E. (2009) Abundance and the environmental niche: Environmental suitability estimated from niche models predicts the upper limit of local abundance. Am. Nat. 174, 282-291. 
Vanhatalo, J., Veneranta, L., Hudd, R. (2012) Species distribution modeling with Gaussian processes: A case study with the youngest stages of sea spawning whitefish (Coregonus lavaretus L. s.1.) larvae. Ecol. Modell. 228, 49-58.

Vital, M.V.C., Hepburn, R., Radloff, S., Fuchs, S. (2012) Geographic distribution of africanized honeybees (Apis mellifera) reflects niche characteristics of ancestral african subspecies. Nat. Conserv. 10, 184-190.

Warren, D.L., Glor, R.E., Turelli, M. (2008) Environmental niche equivalency versus conservatism: quantitative approaches to niche evolution. Evolution 62, 28682883.

Westrich, P., Knapp, A., Berney, I. (2015) Megachile sculpturalis Smith 1853 (Hymenoptera, Apidae), a new species for the bee fauna of Germany, now north of the Alps. Eucera 9, 3-10.

Publisher's note Springer Nature remains neutral with regard to jurisdictional claims in published maps and institutional affiliations. 